\title{
KEPATUHAN KUNJUNGAN ANTENATAL CARE BERDASARKAN FAKTOR MATERNAL
}

\author{
Natiqotul Fatkhiyah, Sri Tanjung Rejeki, Dwi Atmoko \\ Program Studi Diploma III Kebidanan STIKes Bhamada Slawi, Jl. Cut Nyak Dien No.16 Kalisapu Slawi,Tegal \\ natirozak@gmail.com, tanjungrejeki88@gmail.com, atmokodwi120@gmail.com
}

\begin{abstract}
ABSTRAK
Salah satu penyebab Angka Kematian Ibu (AKI) adalah komplikasi dalam kehamilan maupun persalinan. Komplikasi kehamilan dan persalinan dapat dicegah dengan pemeriksaan antenatal care (ANC) secara teratur. ANC merupakan kunjungan ibu hamil dengan tenaga kesehatan untuk mendapatkan pelayanan kehamilan sesuai dengan standar yang ditetapkan. Data yang diperoleh dari puskesmas Slawi bulan Januari-Juni tahun 2019 untuk cakupan kunjungan K1 sebanyak $82,1 \%$ dan cakupan K4 sebanyak $79 \%$.Tujuan penelitian ini untuk mengetahui kepatuhan kunjungan ANC berdasarkan faktor determinan maternal. Penelitian ini menggunakan penelitian kuantitatif dengan pendekatan cross sectional. Sampel pada penelitian sejumlah 30 ibu hamil menggunakan teknik accidental sampling dan analisis data menggunakan uji chi square. Hasil penelitian menunjukan mayoritas usia ibu reproduktif sebesar $66,67 \%$, status multigravida (kehamilan kedua dan ketiga) sebesar $66.67 \%$, kehamilan normal $(60 \%)$ dan telah memenuhi standar K1 sebesar $83.33 \%$ dan memenuhi standar K4 sebesar $86.67 \%$. Ada hubungan antara usia ibu hamil dengan dengan kepatuhan kunjungan ANC ( $p$ value 0,02 ) dan ada hubungan status paritas dengan kepatuhan kunjungan ANC ( $p$ value 0,04 ) dan tidak ada hubungan komplikasi kehamilan dengan kepatuhan kunjungan ANC.
\end{abstract}

Kata kunci : ibu hamil; kepatuhan; antenatal care

\section{ANTENATAL CARE VISIT COMPLIANCE BASED ON MATERNAL FACTORS}

\begin{abstract}
One of the causes of maternal mortality is complications in pregnancy and childbirth. Pregnancy and childbirth complications can be prevented by regular antenatal care visit. ANC is a visit of pregnant women with health workers to get health service in accordance with established standards. Data obtained from Slawi Health Centre in January-June 2019 for coverage of Phase 1 visits was $82.1 \%$ and phase 4 coverage was $79 \%$. The objevtive of this study was to determine the regularity of ANC based on maternal determinants. This study was quantitative research with a cross sectional approach. The number of respondents was 30 pregnant women by using accidental sampling technique. The study was conducted in January-March 2020. Bivariate analysis used chi square test. The results showed that pregnant women who did ANC regularly amounted to $86.67 \%$. The results showed that there was a relationship between age with antenatal care visit because the $p$ value was 0.02 , there was a relationship between parity with antenatal care visit with $p$ value 0.04 , and there was no relationship between pregnancy diagnosis with antenatal care visit because the $p$ value was 0.08 . Pregnant women are expected to perform ANC regularly for early detection of complications in pregnancy.
\end{abstract}

Keywords: pregnant women; compliance; antenatal care 


\section{LATAR BELAKANG}

Angka Kematian Ibu (AKI) merupakan salah satu indikator untuk melihat keberhasilan upaya kesehatan ibu. AKI adalah rasio kematian ibu selama masa kehamilan, persalinan dan nifas yang disebabkan oleh kehamilan, persalinan dan nifas. Salah satu program Sustainable Development Goal (SDG's) pada tahun 2030 yaitu upaya menurunkan AKI agar AKI mencapai $95 \%$ atau 70 Kematian lbu per 100.000 kelahiran hidup (Kementrian Kesehatan $\mathrm{RI}, 2018)$.

Menurut data SDKI (Survei Demografi dan Kesehatan Indonesia), Angka Kematian lbu mengalami penurunan pada periode 1994-2012 yaitu pada tahun 1994 sebesar 390 per 100.000 kelahiran hidup, tahun 1997 sebesar 334 per 100.000 kelahiran hidup, tahun 2002 sebesar 307 per 100.000 kelahiran hidup, tahun 2007 sebesar 228 per 100.000 kelahiran hidup namun pada tahun 2012, Angka Kematian lbu meningkat kembali menjadi sebesar 359 per 100.000 kelahiran hidup. Untuk AKB dapat dikatakan penurunan on the track (terus menurun) dan pada SDKI 2012 menunjukkan angka 32/1.000 kelahiran hidup (SDKI, 2012). Menurut data SUPAS (Survey Penduduk Antar Sensus) tahun baik AKI maupun AKB menunjukkan penurunan (AKI 305/ $100.000 \mathrm{KH}$; AKB 22,23/1.000KH). Dari uraian diatas menunjukkan bahwa Indonesia belum mencapai target dalam hal menurunkan AKI namun telah mencapai target dalam menurunkan AKB (DirKesKel, 2016).

Penyebab kematian ibu hamil secara umum yaitu perdarahan, preeklamsi atau eklamsi dan infeksi. Penyebab kematian ibu dibagi menjadi dua yaitu penyebab langsung dan penyebab tidak langsung, penyebab langsung kematian ibu adalah eklamsi (50\%), perdarahan (16,7\%), infeksi nifas $(16,7 \%)$ serta penyebab obstetric lain $(16,7)$. Sedangkan penyebab tidak langsung meliputi tingkat pendidikan, kondisi lingkungan dan tingkat pelayanan kesehatan bagi ibu hamil, bersalin dan nifas (Retnowati, 2018).

Kehamilan adalah sejak dimulainya konsepsi sampai lahirnya janin lamanya hamil normal adalah 280 hari (40 minggu atau 9 bulan 7 hari) (Prawirohardjo, 2008).
Komplikasi kehamilan dan persalinan dapat dicegah dengan pemeriksaan antenatal care secara teratur. ANC merupakan kunjungan ibu hamil dengan tenaga kesehatan untuk mendapatkan pelayanan ANC sesuai dengan standar yang ditetapkan(Depkes RI 2008).

Menurut Wagiyo dan Purnomo (2016), tujuan ANC adalah memantau kemajuan kehamilan untuk memastikan kesehatan ibu dan tumbuh kembang bayi, Meningkatkan dan mempertahankan kesehatan fisik, mental, dan sosial ibu dan bayi, mengenali secara dini adanya ketidaknormalan atau komplikasi yang mungkin terjadi selama hamil, termasuk riwayat penyakit secara umum, obstetric, dan pembedahan, mempersiapkan persalinan cukup bulan, melahirkan dengan selamat, ibu maupun bayinya dengan trauma seminimal mungkin, mempersiakan ibu supaya masa nifas berjalan normal dan pemberian ASI eksklusif, mempersiapkan peran ibu dan keluarga dalam menerima kelahiran bayi supaya dapat tumbuh dan berkembang secara normal.

Ibu hamil yang tidak teratur melakukan pemeriksaan kehamilan akan terjadi komplikasi yang lebih lanjut yang akan mengakibatkan kematian ibu dan bayi. Sistem penilaian resiko tidak dapat memprediksi apakah ibu hamil bermasalah selama kehamilanya. Oleh karena itu, pelayanan / asuhan antenatal merupakan cara penting untuk memonitor dan mendukung kesehatan ibu hamil normal dan mendeteksi ibu dengaan kehamilan normal (Saiffudin, 2014).

Penelitian yang dilakukan Tewodos,etc (2009) menyatakan pemeriksaan ANC dipengaruhi beberapa faktor seperti pengetahun, pendidikan, paritas, pekerjaan, status ekonomi, sikap dan kualitas pelayanan ANC.Kunjungan ANC minimal 4 kali selama kehamilan, satu kali pada trimester I, satu kali pada trimester II dan dua kali pada trimester III (Pantikawati 2010).

Studi pendahuluan yang dilakukan pada Bulan Oktober 2019 di Puskesmas Slawi, Kabupaten Tegal, diperoleh data jumlah keseluruhan ibu hamil di Puskesmas Slawi, Kabupaten Tegal, pada bulan Januari sampai Desember 2018 sebanyak 1.367 ibu hamil dengan cakupan kunjungan K1 sebanyak 93,4\% dan cakupan kunjungan K4 sebanyak $84,5 \%$. 
Adapun data yang diperoleh untuk tahun 2019 ( Januari-Juni) terdapat sebanyak 1290 ibu hamil cakupan wilayah kerja Puskesmas Slawi dengan cakupan kunjungan K1 sebanyak 82,1\% dan cakupan K4 sebanyak 79\%. Adapun untuk hasil wawancara yang dilakukan pada 5 orang ibu hamil tentang antenatal care dengan hasil 1 orang ibu hamil berpengetahuan baik, dan 4 orang berpengetahuan cukup.

lbu hamil perlu mengetahui tentang pentingnya kunjungan antenatal care secara teratur untuk mendeteksi secara dini komplikasi yang terjadi selama kehamilan. Maka dari itu penulis tertarik untuk melakukan penelitian dengan judul "Keteraturan Kunjungan ANC Di Wilayah Kerja Puskesmas Slawi, Kab. Tegal". Tujuan penelitian untuk mengetahui faktor determinan maternal.yang berhubungan dengan kepatuhan ANC.

\section{METODE}

Metode penelitian ini menggunakan penelitian kuantitatif dengan jenis penelitian deskriptif. Penelitian dilakukan pada Januari- Maret 2020. Sampel dalam penelitian ini berjumlah 30 ibu hamil trimester III menggunakan tekhnik pengambilan data accidental sampling. Kriteria inklusi yang digunakan yaitu lbu hamil trimester III yang memeriksakan kehamilannya di Puskesmas Slawi serta bersedia menjadi responden. Penelitian ini menggunakan data primer dan sekunder. Data primer berupa usia ibu, paritas, dan komplikasi kehamilan. Sedangkan data sekunder berupa tanggal dan frekuensi kunjungan ANC dengan melihat buku $\mathrm{KIA}$. Teknik pengumpulan data dengan data sekunder yaitu kohort ibu hamil. Teknik analisis data menggunakan uji chi Square. Etika dalam penelitian ini meliputi informed consent, anonymity dan confidentiality.

\section{HASIL}

Analisis univariat pada penelitian ini menggambarkan variabel independent (usia ibu, paritas, diagnosa kehamilan) dan variabel dependen (kepatuhan kunjungan ANC) yang digambarkan pada tabel 1 .

\section{Tabel 1 Gambaran Karakteristik Responden Berdasarkan Usia Ibu, Paritas, Diagnosa Kehamilan, K1 dan K4 Di Wilayah Kerja Puskesmas Slawi $(n=30)$}

\begin{tabular}{lcc}
\hline Variabel & f & $\begin{array}{c}\text { Persentase } \\
(\%)\end{array}$ \\
\hline Usia lbu & & \\
$\quad<20$ tahun & 0 & 0.0 \\
$20-35$ tahun & 20 & 66,67 \\
$>35$ tahun & 10 & 33,33 \\
& & \\
Paritas & & \\
$\quad$ Primi(1) & 8 & 26.67 \\
$\quad$ Multi (2-3) & 20 & 66.67 \\
$\quad$ Grande ( $\geq 4)$ & 2 & 6.66 \\
& & \\
Kehamilan & & \\
$\quad$ Normal & 18 & 60.0 \\
$\quad$ Komplikasi & 12 & 40.0 \\
K1 & & \\
$\quad$ Sesuai standar & 25 & 83.33 \\
Tidak sesuai & 5 & 16.67 \\
& & \\
K4/kepatuhan & & 86.67 \\
$\quad$ Sesuai standar & 26 & 13,33 \\
$\quad$ Tidak sesuai & 4 & \\
\hline
\end{tabular}

Tabel 1 menunjukkan hasil yang dominan pada variabel riset yaitu usia ibu reproduktif sebesar $66,67 \%$, status multigravida (kehamilan kedua dan ketiga) sebesar $66.67 \%$, kehamilan normal $(60 \%)$ dan telah memenuhi standar K1 sebesar $83.33 \%$ dan memenuhi standar K4 sebesar $86.67 \%$. 
Analisi bivariat berikut ini digunakan untuk mengatuhi hubungan antara usis ibu, paritas, Diagnosa kehamilan dengan kepatuhan antenatal care (Tabel 2).

Tabel 2. Hubungan Usia, Paritas, Diagnosa Kehamilan dengan Kepatuhan Antenatal Care (K4) di Wilayah Kerja Puskesmas Slawi $(n=30)$

\begin{tabular}{|c|c|c|c|c|c|c|c|}
\hline \multirow[t]{2}{*}{ Variabel } & \multicolumn{2}{|c|}{$\begin{array}{l}\text { Sesuai } \\
\text { standar }\end{array}$} & \multicolumn{2}{|c|}{$\begin{array}{l}\text { Tidak sesuai } \\
\text { standar }\end{array}$} & \multicolumn{2}{|c|}{ Total } & \multirow{2}{*}{$\begin{array}{c}p \\
\text { value }\end{array}$} \\
\hline & $F$ & $\%$ & $F$ & $\%$ & $F$ & $\%$ & \\
\hline \multicolumn{8}{|l|}{ Usia lbu } \\
\hline$<20$ tahun & 0 & 0 & 0 & 0 & 0 & 0 & 0.02 \\
\hline 20-35 tahun & 16 & 80 & 4 & 20 & 20 & 100 & \\
\hline$>35$ tahun & & 70 & 3 & 30 & 10 & 100 & \\
\hline \multicolumn{8}{|l|}{ Paritas } \\
\hline Primi (1) & 3 & 37.5 & 5 & 62.5 & 8 & 100 & 0.04 \\
\hline Multi (2-3) & 11 & 85 & 3 & 15 & 20 & 100 & \\
\hline Grande $(\geq 4)$ & & 100 & 0 & 0 & 2 & 100 & \\
\hline \multicolumn{8}{|l|}{ Diagnosis } \\
\hline Kehamilan & & & & & & & \\
\hline Normal & 18 & 78,2 & 5 & 21.7 & 23 & 100 & 0.08 \\
\hline Komplikasi & 7 & 100 & 0 & 0 & 7 & 100 & \\
\hline
\end{tabular}

Tabel 2 menunjukkan ibu hamil yang teratur melakukan ANC sebagian besar pada kelompok usia ibu 20-30 tahun sebesar 80\%, multigravida $(85 \%)$ dan kehamilan normal (100\%). Dari hasil analisis menggunakan uji chi square dengan program SPSS didapatkan nilai Asym. Sig sebesar 0.02 ( $p$ value $<0,05)$ sehingga dapat disimpulkan ada korelasi usia reproduksi dengan kepatuhan kunjungan ANC. Pada status paritas didapat didapatkan nilai Asym. Sig sebesar 0.04 ( $p$ value $<0,05$ ) sehingga dapat disimpulkan ada korelasi paritas dengan kepatuhan kunjungan ANC, namun diagnosis kehamilan tidak berhubungan dengan kepatuhan kunjungan ANC karena nilai Asym. Sig sebesar 0.08 ( $p$ value $>0,05$ ).

\section{PEMBAHASAN}

Ante natal care adalah pelayanan yang diberikan oleh ibu hamil secara berkala untuk menjaga kesehatan ibu dan bayinya. Pelayanan antenatal ini meliputi pemeriksaan kehamilan, upaya koreksi terhadap penyimpangan dan intervensi dasar yang dilakukan (Pantikawati, 2010).

Berdasarkan hasil penelitian menunjukkan sebagian besar ibu hamil teratur melakukan kunjungan ANC.Menurut WHO dan Depkes RI 2015, kunjungan ANC sebaiknya dilakukan 4 kali selama kehamilan yaitu satu kali pada trimester pertama (K1) dengan usia kehamilan 1 - 12 minggu untuk mendapatkan pemeriksaan kehamilan, perencanaan persalianan dan pelayanan kesehatan trimester pertama.Satu kali pada trimester kedua (K2) dengan usia kehamilan 13 - 24 minggu untuk mendapatkan pelayanan antenatal sesuai standar selama satu periode berlangsung dan dua kali pada trimester ketiga (K3 \& K4) dengan usia kehamilan >24 minggu untuk memantapkan rencana persalinan dan mengenali tanda-tanda persalinan.

Hasil penelitian menunjukkan ibu hamil yang melakukan ANC secara teratur berada direntang usia 20-35 tahun. Hal tersebut menunjukkan sebagian besar ibu hamil berada dalam rentang usia reproduksi sehat. Usia 2035 tahun merupakan usia yang matang bagi seorang wanita sehingga pada usia tersebut seseorang mempunyai keinginantahuan dan kepedulian yang besar terhadap kehamilannya serta kesadaran yang tinggi untuk melakukan kunjungan ANC secara teratur. Hal ini sesuai dengan penelitian Mufidah (2010) yaitu ibu hamil yang melakukan pemeriksaan ANC secara teratur sebagian besar pada usia 20-35 tahun. Hasil penelitian juga sesuai dengan penelitian yang dilakukan Dairi dan Owoyokun yang menyatakan ibu hamil yang berusia 20-34 
tahun memanfaatkan pelayanan ANC lebih baik daripada ibu hamil dengan usia $<20$ tahun dan $>35$ tahun. Hasil penelitian juga menunjukkan adanya hubungan antara usia dengan kepatuhan kunjungan ANC hal ini sesuai dengan penelitian Putri shinta yang menyatakan adanya hubungan usia dengan kepatuhan kunjungan ANC di Puskesmas Suruh Kabupaten Semarang. Menurut Green (2005) Usia seseorang menjadi salah satu faktor yang mempengaruhi seseorang untuk melakukan perubahan perilaku kesehatan. Usia mempengaruhi daya tangkap dan pola pikir seseorang. Semakin bertambahnya usia akan semakin berkembang pula daya tangkap dan pola pikir, sehingga pengetahuan yang diperoleh semakin membaik, hal ini sebagai akibat dari pengalaman dan kematangan jiwanya.

Menurut Prawirohardjo (2012) Kematian maternal pada wanita hamil dan melahirkan meningkat 2 sampai 5 kali pada usia dibawah 20 tahun dibandingkan pada ibu hamil berusia 20-35 tahun dan kematian maternal akan meningkat kembali sesudah usia 35 tahun. Hal ini sesuai dengan hasil penelitian bahwa ibu hamil yang berusia 20-35 tahun melakukan kunjungan ANC secara teratur untuk memastikan kesehatan ibu dan janinnya serta deteksi dini adanya komplikasi pada kehamilan

Penelitian ini menunjukkan hasil bahwa ibu hamil yang teratur dalam melakukan ANC adalah ibu hamil multigravida sebanyak $85 \%$. Hal ini sesuai denggan penelitian Rauf (2013) yang menyatakan ibu hamil dengan paritas lebih dari satu yang memanfaatkan pelayanan mengatakan bahwa terdapat risiko pada kehamilan sebelumnya sehingga merasa perlu untuk memeriksakan kehamilan secara teratur sedangkan ibu dengan kehamilan yang pertama akan termotivasi melakukan pemeriksaan ANC karena merupakan hal yang baru. Hasil penelitian juga menunjukkan hasil ada hubungan antara paritas dengan kepatuhan ANC hal ini sesuai dengan penelitian Daryanti
2019 yang menyatakan paritas berhubungan dengan pemeriksaan ANC pada ibu hamil di PMB Sleman Yogyakarta. Ibu hamil dengan paritas tinggi lebih berisiko mengalami komplikasi dan kematian lebih tinggi dibanding ibu hamil dengan paritas rendah, sehingga ibu hamil dengan paritas tinggi akan memeriksakan kehamilannya secara teratur ke tenaga kesehatan.

Hasil penelitian menunjukkan diagnosis kehamilan tidak ada hubungan dengan kepatuhan ANC, karena baik diagnosis kehamilan normal maupun tidak, ibu hamil patuh melakukan kunjungan ANC secara teratur. Kehamilan dalam perkembangannya mempunyai risiko mengalami penyulit dan komplikasi oleh karena itu pelayanan antenatal harus dilakukan secara rutin, terpadu dan sesuai standar pelayanan antenatal yang berkualitas. Pelayanan diupayakan agar memenuhi standar kualitas, seperti Penimbangan berat badan dan pengukuran tinggi badan, pengukuran tekanan darah, pengukuran lingkar lengan atas (LILA), pengukuran tinggi puncak rahim (Fundus uteri), penentuan status imunisasi tetanus dan pemberian imunisasi tetanus toxoid sesuai status imunisasi, pemberian tablet tambah darah 90 tablet selama kehamilan, penentuan presentasi janin dan denyut jantung janin (DJJ), pelaksanaan temu wicara, pelayanan tes laboratorium sederhana, minimal tes hemoglobin darah $(\mathrm{Hb})$ dan atalaksana kasus. (Wagiyo \& Putrono 2016).

\section{KESIMPULAN DAN SARAN}

Ada hubungan antara usia ibu hamil, status paritas dengan kepatuhan kunjungan ANC. Tidak ada hubungan diagnosa kehamilan dengan kepatuhan kunjungan ANC. Diharapkan ibu hamil melakukan ANC secara teratur untuk deteksi awal komplikasi dalam kehamilan dan tenaga kesehatan memberikan pelayanan ANC sesuai standar prosedur operasional. 


\section{REFERENSI}

Dairo, M.D, Owoyokun, K.E. Factor Effecting the Utilization of antenatal care services in Ibadab Nigeri. Departemet of Epidemiology \& medical Statistic, College of medicine, $\mathrm{UCH}$, Ibadan. 12 (1), 3-13 June 2,2012

Daryanti. (2019). Paritas Berhubungan dengan

Pemeriksaan ANC pada Ibu Hamil di PMB Sleman Yogyakarta. Jurnal Kebidanan 8 (1) 2019

Depkes RI. (2015). Pedoman Pelayanan Antenatal Care. Depkes RI. Jakarta

Depkes RI. (2009). Buku Kesehatan Ibu dan Anak (KIA). Jakarta : Depkes RI dan JICA.

Dirkeskel. (2016). Laporan Tahunan Direktorat Kesehatan Keluarga. Jakarta: Laptah

Green. (2005). Health Program Planning An Educational and Ecol ogical Approach. New York: Me Graw Hill.

Kementrian Kesehatan RI. (2018). Profil Kesehatan Indonesia Tahun 2018. Indonesia: Kementran Kesehatan RI

Mufidah L, dkk.(2010). Hubungan Usia Ibu Hamil Trimester 3 dengan Keteraturan Antenatal Care K4 di BPS Ny S Desa Sidomukti Kecamatan Lamongan Kabupaten Lamongan. Surya. Vol 01 (V) April 2010

Pantikawati dan Saryono. (2010). Asuhan Kebidanan I (Kehamilan). Yogyakarta : Nuha Medika.
Prawirohardjo, Sarwono. (2008). IImu Kebidanan. Jakarta: Yayasan Bina Pustaka.

Prawirohardjo, Sarwono. (2012). IImu Kebidanan. Jakarta: Yayasan Bina Pustaka.

Putri,Shinta, dkk. (2015). Hubungan Usia Ibu Hamil Dengan Kepatuhan ANC di Puskesmas Suruh Kabupaten Semarang. Jurnal Keperawatan Maternitas Vol 3 (1) Mei 2015

Rauf, N dkk. (2013). Factor Related to the Utilization of antenatal Care at Publik Health Center Of Minasa UPA Makasar, 1 11

Retnowati. (2018). Analisis motivasi ibu hamil dalam mengikuti kelas ibu hamil di daerah pesisir wilayah kerja Puskesmas Pantai Amal Kota Tarakan. Journal of Borneo Holistic Health volume 1 no 2. ISSn 2621-9514

Saiffudin, Abdul dkk. (2014). Pelayanan Kesehatan Maternal dan Neonatal. Jakarta : PT. BinaPustaka

Tewodros B, etc. (2009). Factor Affecting Antenatal care Utilization in Yem Special Woreda, Southweatern Ethiophia. Ethiop J Health Sci, 19 (1), 45-51

Wagiyo \& Purnomo. (2016). Asuhan Keperawatan Antenatal, Intranatal, Dan Bayi Baru Lahir. Yogyakarta: Penerbit AND 